\title{
Differentiation of non-black fillers in rubber composites using linear discriminant analysis of principal components
}

https://doi.org/10.1515/secm-2019-0010

Received February 15, 2019; accepted Aprl 4, 2019

\begin{abstract}
In the compounding of rubber composites, different non-black fillers are used to improve the physical properties, reduce the formulation cost, and provide special characteristics. Designing a rubber composite for a specific application needs the careful selection and differentiation of fillers based on its effect on processibility and overall material properties of the vulcanizate. However, fillers are usually classified according to their effect on reinforcement or function without much consideration to other properties such as vulcanization characteristics and heat aging resistance. Analyses of multiple properties are tedious when done in a univariate way. To differentiate non-black fillers with consideration to the various properties of rubber composites, linear discriminant analysis (LDA) of principal components (PCs) was used. This paper examines how vulcanization and mechanical properties can differentiate aluminosilicate, bentonite, and silica fillers in rubber composites.

Aluminosilicate and silica were effectively differentiated from bentonite using the vulcanization characteristics and mechanical properties of rubber composites before heat aging. Better differentiation among the 3 non-black fillers was achieved when the mechanical properties of rubber composites after heat aging were included in the PC analysis. LDA required at least 6 PCs to correctly classify the non-black filler in 30 rubber composites.
\end{abstract}

Keywords: principal component analysis (PCA); linear discriminant analysis (LDA); non-black filler; rubber composite

\footnotetext{
^Corresponding Author: Bryan B. Pajarito : Polymer Research Laboratory, Department of Chemical Engineering, University of the Philippines, Diliman, Quezon City 1101 Philippines, E-mail: bryan.pajarito@gmail.com
}

\section{Introduction}

Fillers are mainly used in rubber compounding to enhance the physical properties of rubber composites. They can also be utilized to lower the cost of rubber compounds and impart special properties such as color, impermeability, oil resistance, etc. $[1,2]$. The rubber industry employs a wide range of fillers. Carbon black has been the most important filler for rubber composites in terms of reinforcement $[1,2]$. However, the dependence of carbon black from petroleum feedstock, its polluting nature, and imposed restriction in color have prompted rubber manufacturers to use non-black fillers [3-9]. Among non-black fillers, precipitated silica provides the highest degree of reinforcement [10]. Other non-black fillers include clays, calcium carbonate, silicates, talc, and metal oxides [1, 2, 10-12]. Silane coupling agents improve the chemical compatibility of non-black fillers with rubber matrices for more efficient reinforcement $[1,2,6,7,9,10,12]$. Recently, rubber nanocomposites demonstrate excellent mechanical properties due to the addition of organoclay at low loadings [13-15]. The organic modification of clay using quaternary ammonium salts allows intercalation and exfoliation of clay nanoplatelets in the rubber matrix. This translates to improved dispersion of the non-black filler in the rubber matrix and enhanced reinforcement.

Design of rubber composites for a specific application requires the particular selection of the type of filler. With a large number of fillers available in the market, rubber manufacturers must be able to differentiate fillers from one type to another based on its effect on the processibility and the final material properties of the rubber composite. However, fillers are currently classified according to their reinforcing effect or function. Waddell and Evans [10, 11] categorized non-black fillers as nonreinforcing, semi-reinforcing, reinforcing, or highly reinforcing based on the surface area of the filler and the corresponding hardness of the rubber compound. Mouri [2] differentiated non-black fillers according to function: reinforcing, diluent, or those adding special traits like color, electrical conductivity, flame resistance, etc. Aside from physical reinforcement, non-black fillers also affect other 
important properties of rubber composites such as vulcanization characteristics and heat aging resistance $[3,4,16-$ 19]. Analysis of material properties is usually performed in a univariate approach, where each property is investigated separately from the others. Such a method of analysis is slow and difficult especially when a large number of properties is involved. On the other hand, a multivariate approach in analyzing the material properties results in the retrieval of global information from all the properties at the same time [20].

In order to examine various material properties simultaneously for the differentiation of non-black fillers in rubber composites, linear discriminant analysis (LDA) was used. LDA classifies an observation into a group if the Mahalanobis squared distance of the observation to the group center is the minimum. Each group has a linear discriminant function. For each observation, the group with the smallest squared distance has the largest discriminant function [21-23]. In this study, an observation corresponds to a set of material properties measured from a sample of the rubber composite. Meanwhile, a group indicates a known type of filler used to prepare the rubber composite.

In this study, 19 different material properties were measured from a set of 30 experimental rubber composites. The analyzed properties were vulcanization characteristics (minimum and maximum elastic torques, scorch and curing times, cure rate index) and mechanical properties (tensile stress at specified elongations, tensile strength, strain at break, hardness) before and after heat aging. Rubber compounders use these properties to compare and assess different product formulations. A high correlation exists among the analyzed properties (multicollinearity), e.g. maximum elastic torque correlates with tensile properties and hardness of rubber [24]. Multicollinearity decreases the classification ability of LDA [23] with the discriminant function poorly predicting the membership of observation into a group. Following the suggestion of Næs and Mevik [23], the principal components (PCs) were first derived from the data set of properties and used it as input to LDA. PCs are uncorrelated variables that are linear combinations of the observed variables [25], e.g. the measured properties of the rubber composite. A few PCs can represent an appreciable amount of variation present in the original variables $[25,26]$. In other fields of research, LDA of PCs has been successfully used to differentiate bricks [27], olive cultivars [28], fishes [29], ballpoint pen inks [30], gasoline [22], olive oils [31], and wines [32].

This paper evaluates how vulcanization characteristics and mechanical properties before and after heat aging of rubber composites differentiate and predict the type of non-black filler using LDA of PCs. This paper also deter- mines which specific set of material properties, e.g. vulcanization characteristics, mechanical properties, or combined, best discriminate between different types of nonblack filler in rubber composites.

\section{Experimental}

\subsection{Materials}

Three types of non-black fillers were used as received: naturally occurring aluminosilicate surface-treated with trimethylsilane (Silatherm T 1360, HPF The Mineral Engineers Quarzwerke $\mathrm{GmbH}$ ), natural bentonite (industrial grade, Saile Industries Inc.), and synthetically produced amorphous silica (Silmikron 1171-850, HPF The Mineral Engineers Quarzwerke GmbH). Table 1 shows the chemical composition, loss on ignition, and median particle size of aluminosilicate, bentonite, and silica fillers obtained from the product data sheets. According to the product data given by suppliers, the aluminosilicate improves the thermal conductivity of polymers. Bentonite serves as a diluent and lowers the cost of rubber compounds. Silica has high purity and spherical particle shape with key applications in technical rubber parts.

Standard Philippine rubber (SPR 10), zinc oxide, stearic acid, sulfur, and N-tert-butyl-2-benzothiazyl sulfonamide (TBBS) were provided by a local compounder (Rhodeco Rubber Processing Services Corp).

\subsection{Compounding and vulcanization of rubber composites}

Raw natural rubber was first masticated with aluminosilicate, bentonite, or silica at 10 different proportions (2.5, 5.0, 7.5, 10.0, 12.5, 15.0, 17.5, 20.0, 22.5, and $25.0 \mathrm{phr}$ ) using a laboratory mixing mill at room temperature. After achieving homogenous filler dispersion, the rubber mixture was then compounded with $5 \mathrm{phr}$ zinc oxide, $2 \mathrm{phr}$ stearic acid, $2.5 \mathrm{phr}$ sulfur, and $0.6 \mathrm{phr}$ TBBS. The final weight of the rubber compound was $1000 \mathrm{~g}$. Vulcanization of rubber compound was performed using a compression molding press at $160^{\circ} \mathrm{C}$. The dimensions of the vulcanized sheets of rubber composite were $300 \times 300 \times 3 \mathrm{~mm}$.

\subsection{Measurement of material properties}

Vulcanization characteristics of rubber composites were obtained at $160{ }^{\circ} \mathrm{C}$ using a moving die rheometer (EKT- 
Table 1: Chemical composition, loss on ignition, and median particle size of aluminosilicate, bentonite, and silica.

\begin{tabular}{lccc}
\hline Chemical composition (wt\%) & Aluminosilicate & Bentonite & Silica \\
\hline $\mathrm{SiO}_{2}$ & 43.0 & 47.9 & $>99.0$ \\
$\mathrm{Al}_{2} \mathrm{O}_{3}$ & 55.0 & 14.0 & - \\
$\mathrm{Fe}_{2} \mathrm{O}_{3}$ & 0.5 & 7.5 & - \\
$\mathrm{CaO}+\mathrm{MgO}$ & 0.1 & 6.4 & - \\
$\mathrm{Na}_{2} \mathrm{O}+\mathrm{K}_{2} \mathrm{O}$ & 0.1 & 0.8 & - \\
Loss on ignition & 0.3 & 12.3 & 0.2 \\
Median particle size $(\mu \mathrm{m})$ & 5.0 & 131.8 & 0.3 \\
\hline
\end{tabular}

2000S, Ektron Tek Co., Ltd). Seven variables related to vulcanization characteristics were obtained for each sample of rubber composite: minimum (ML) and maximum (MH) elastic torques, scorch times ts1 and ts2, cure times tc50 and tc90, and cure rate index CRI [33].

Dumbbell-shaped specimens were cut from vulcanized sheets of rubber composite and were subjected to tensile testing using a universal testing machine (AGS-5kN, Shimadzu) following ASTM D412. The crosshead speed was $500 \mathrm{~mm} \mathrm{~min}^{-1}$. Hardness was measured using a Shore A durometer (Kori Seiki) according to ASTM D2240. Six variables related to mechanical properties were determined for each sample of rubber composite: tensile stress at 100,200 , and $300 \%$ strain (100\%Mod, $200 \%$ Mod, and $300 \% \mathrm{Mod}$ ), tensile strength (TS), strain at break (SB), and hardness. At least 5 replicate specimens were tested and the average values were used in data analysis.

The tensile properties and hardness of the rubber composite were also measured after heat aging following ASTM D573. The rubber specimen was aged in a laboratory oven (FD 53, Binder $\mathrm{GmbH}$ ) at $70{ }^{\circ} \mathrm{C}$ for $336 \mathrm{~h}$. The aged specimen was cooled at room temperature before testing. This procedure generated another set of 6 variables (A$100 \%$ Mod, A-200\%Mod, A-300\%Mod, A-TS, A-SB, and AHardness) related to the mechanical properties of rubber composite after heat aging.

\subsection{Data analysis}

Minitab 17 was used to perform PC analysis (PCA) and LDA. Due to the difference in scales of the material properties, the correlation type of matrix was used to calculate the PCs.

Three original sets of material properties were obtained from actual testing of rubber composites: vulcanization characteristics (V; Table A1) and mechanical properties before (M; Table A2) and after (MA; Table A3) heat aging. Additional sets of material properties were gener- ated from the original sets, e.g. $\mathrm{V}+\mathrm{M}, \mathrm{V}+\mathrm{MA}, \mathrm{M}+\mathrm{MA}$, and $\mathrm{V}+\mathrm{M}+\mathrm{MA}$. The original and additional sets of material properties were used as inputs in PCA. This was performed to determine which specific set of material properties best differentiate between aluminosilicate, bentonite, or silica filler in rubber composites.

\section{Results and discussion}

The minimum number of PCs needed to represent the variation in the material properties of rubber composite depends on the type of data input (see Figure 1). Following Kaiser's rule [25], the first PC (PC1) already captures the variation in the mechanical properties of rubber composite before heat aging (data input M). The variations in vulcanization characteristics (data input $V$ ) and mechanical properties after heat aging (data input MA) require at least the first $2 \mathrm{PCs}$. Combining data inputs does not significantly increase the required number of PCs, e.g. first 2 PCs for $\mathrm{V}+\mathrm{M}$ and $\mathrm{M}+\mathrm{MA}$; first $3 \mathrm{PCs}$ for $\mathrm{V}+\mathrm{MA}$ and $\mathrm{V}+\mathrm{M}+\mathrm{MA}$. The eigenvalue at $\mathrm{PC} 1$ increases with the number of material properties included in the data input. Each material property in the data input has a variation that contributes to the magnitude of PC1's eigenvalue $[25,26]$.

The PC1 calculated from data inputs M, MA, and M + MA explains more than $75 \%$ of the variation in the material properties (see Figure 2). Meanwhile, the PC1s from the other data inputs only retain $50-65 \%$ of the initial information. The addition of the second PC (PC2) further increases the amount of retained information by more than $80 \%$ in all data inputs. Four PCs allow more than $95 \%$ of the relevant information from the different data inputs to be explained.

Aluminosilicate and silica composites can be differentiated from bentonite composites using vulcanization characteristics as sole input to PCA (see Figure 3A). The difference in elastic torque (ML and $\mathrm{MH}$ ) and cure rate (CRI) 


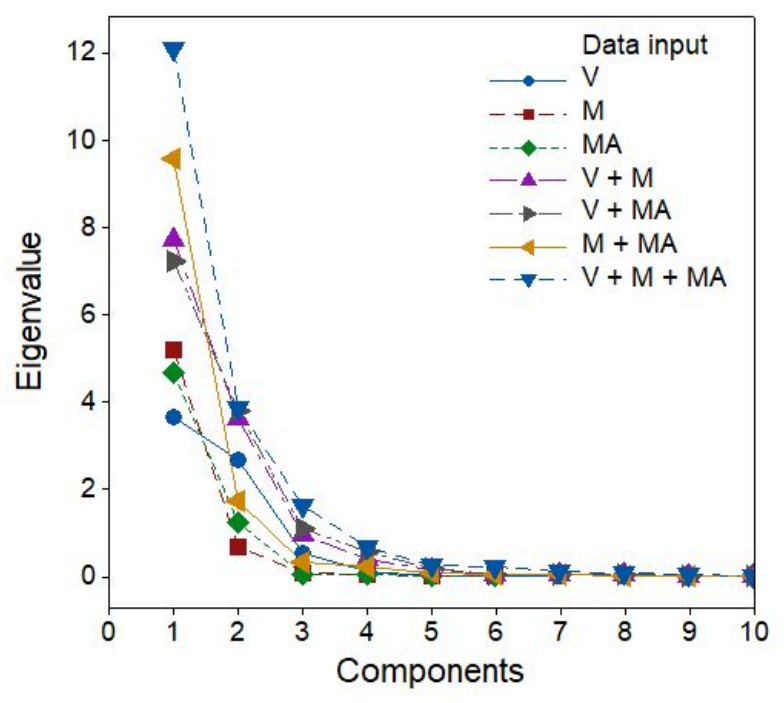

Figure 1: Eigenvalue as function of the number of PCs for different data inputs.

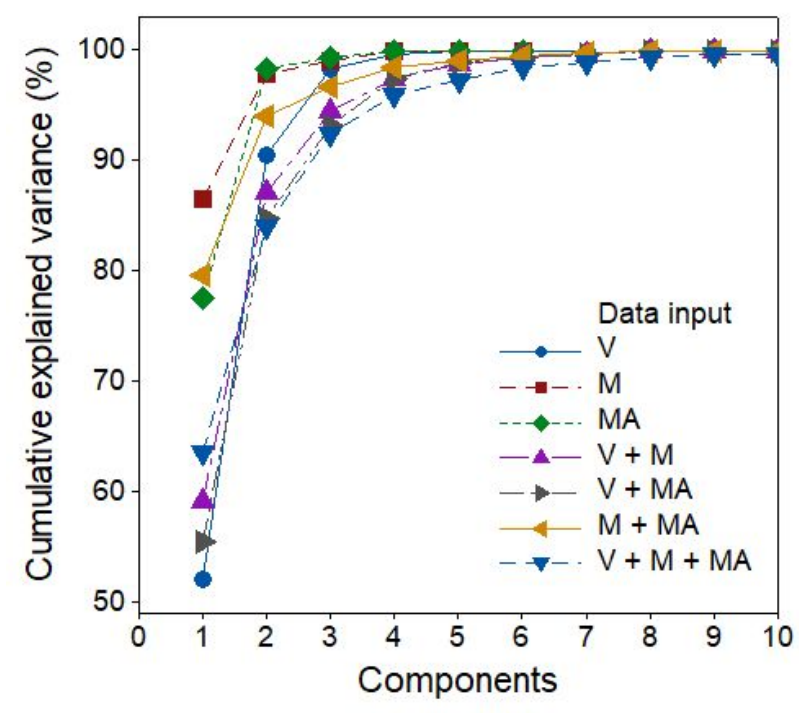

Figure 2: Cumulative explained variance as function of the number of PCs for different data inputs.

enables the separation of the 2 non-black fillers from bentonite (see Figure 3B). Both aluminosilicate and silica have surface areas higher than bentonite due to their smaller particle size which contribute to high viscosity and elastic torque of rubber composites [34]. All aluminosilicate composites have negative PC1 values where CRI is positively associated. Silane treatment of the aluminosilicate contributes to the increase in the cure rate [35].

Aluminosilicate and silica composites can also be distinguished from bentonite composites using mechanical properties of unaged samples (see Figure 4A). The cluster- ing of aluminosilicate and silica composites in the positive $\mathrm{PC} 1$ axis indicates higher tensile stress at varied strains (100\%Mod, 200\%Mod, and 300\%Mod) and hardness than bentonite composites (see Figure 4B). Similar to elastic torque, the high surface areas of aluminosilicate and silica also increase the tensile stress responses and hardness of rubber composites [34].

The use of mechanical properties of heat-aged samples in PCA results in better discrimination among the 3 non-black fillers (see Figure 5A). Aluminosilicate and silica composites are differentiated from bentonite composites in the $\mathrm{PC} 1$ axis due to high tensile stress responses and hardness (see Figure 5B). PC2 separates the aluminosilicate from silica composites through the values of A-TS and A-SB. After heat aging, silica composites have higher TS and SB than aluminosilicate composites.
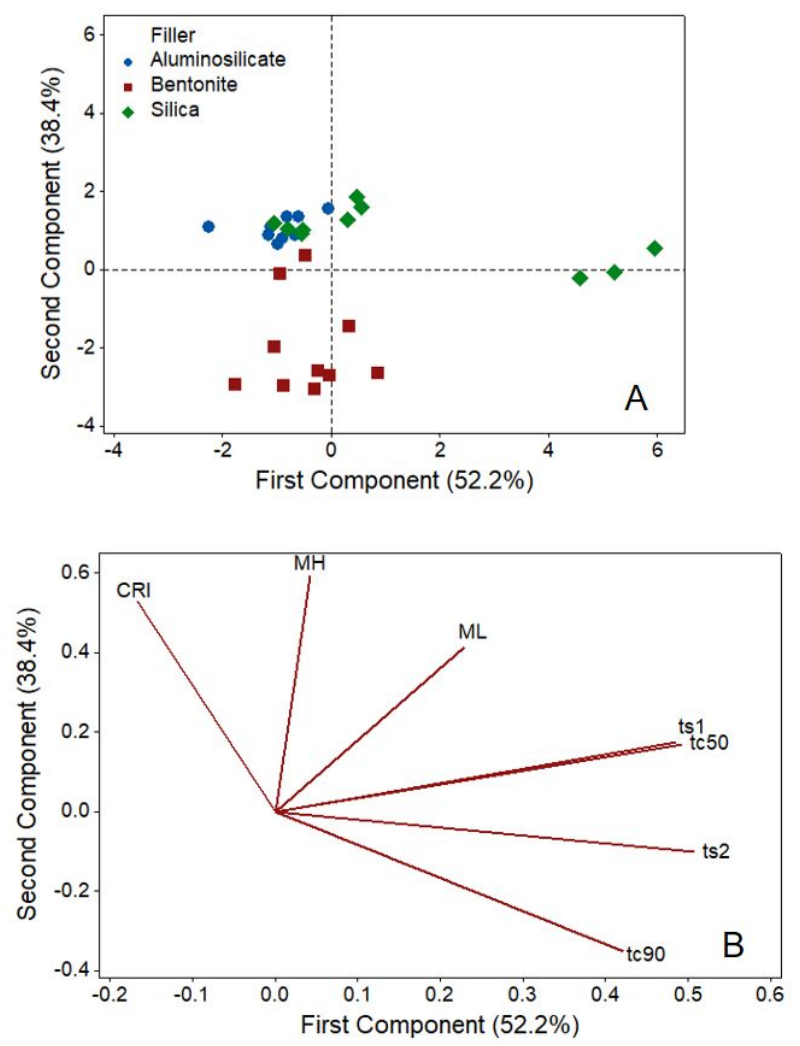

Figure 3: PCA of data input V. Distribution plots of the rubber composites (A) and material properties (B) on PC1 and PC2.

Clustering of rubber composites according to the type of filler also occurs when different material properties are combined as input to PCA (see Figure 6). Aluminosilicate and silica composites are easily distinguished from bentonite composites with data input $\mathrm{V}+\mathrm{M}$ (see Figure 6A) 

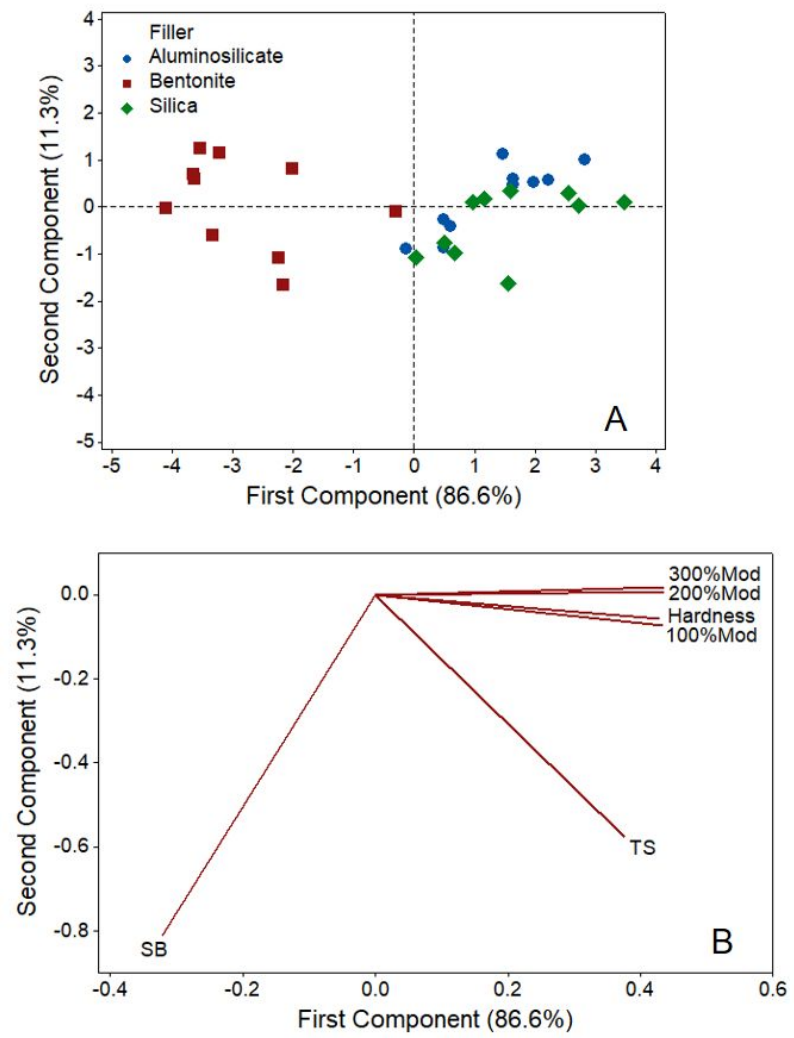

Figure 4: PCA of data input $M$. Distribution plots of the rubber composites (A) and material properties (B) on $P C 1$ and $P C 2$.

where the PC1 axis is heavily influenced by ML, MH, tensile stress at varied strains, TS, SB, and hardness (see Figure $7 \mathrm{~A}$ ). With the addition of mechanical properties of heat-aged rubber composites in the data input, i.e. $\mathrm{V}+$ MA (Figure 6B), $M+M A$ (Figure 6C), and $V+M+M A$ (Figure 6D), aluminosilicate is differentiated from silica. In data inputs $\mathrm{V}+\mathrm{MA}$ and $\mathrm{M}+\mathrm{MA}$, aluminosilicate composites have higher PC2 values than silica composites. On this direction, the discrimination is mainly due to the variation in scorch and curing times, TS and SB before and after heat aging of rubber composites (see Figure 7B and 7C). In data input $V+M+M A$ (see Figure 6D), aluminosilicate is separated from silica in the PC2 axis mainly due to differences in scorch and curing times and A-SB (see Figure 7D).

The loading plot from data input $\mathrm{V}+\mathrm{M}+\mathrm{MA}$ (see Figure 7D) shows the type of correlation among the 19 material properties of rubber composites. MH strongly correlates with the mechanical properties of unaged and aged samples (positive correlation with tensile stress at varied strains and hardness; negative with SB). This confirms the use of $\mathrm{MH}$ as a good indicator of tensile properties and hardness of rubber vulcanizates [24] even after heat aging. At the same time, ML correlates well with the TS of heat-
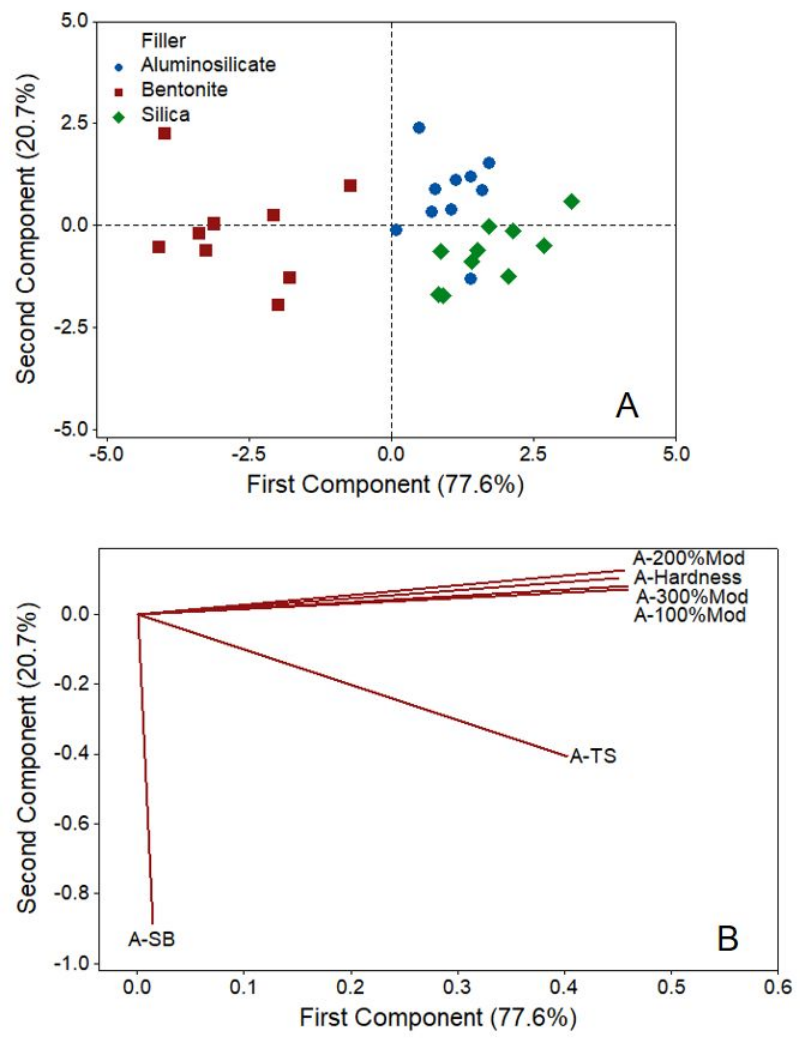

Figure 5: PCA of data input MA. Distribution plots of the rubber composites (A) and material properties (B) on PC1 and PC2.
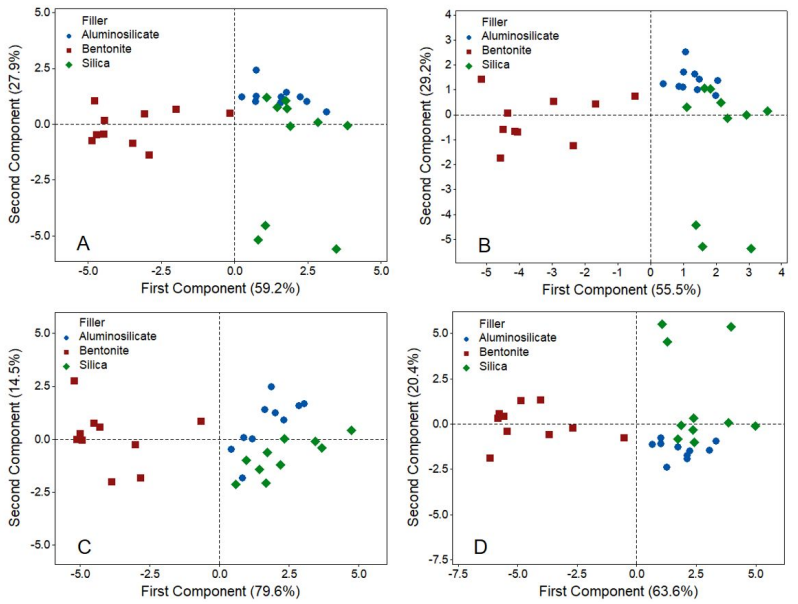

Figure 6: Distribution plots of the rubber composites on $P C 1$ and $P C 2$ for the generated data inputs: $V+M(A), V+M A(B), M+M A(C)$, and $V+M+M A(D)$.

aged samples. Meanwhile, the negative correlation of CRI with ts 2 and tc90 is due to the given inverse relationship between these parameters [33].

LDA reveals that when 2 PCs are used (which explains $>80 \%$ of the total variation in the data input), the classification of non-black filler in the rubber composites ranges 

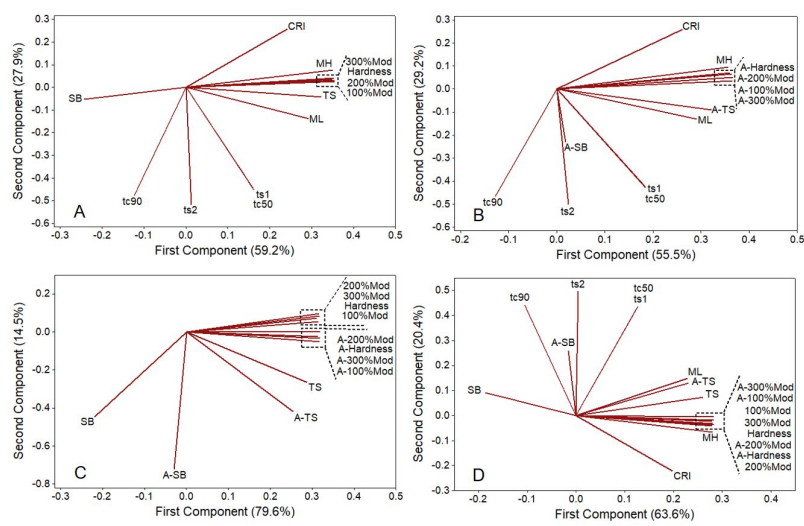

Figure 7: Distribution plots of the material properties on $P C 1$ and $P C 2$ for the generated data inputs: $V+M(A), V+M A(B), M+M A(C)$, and $V+M+M A(D)$.

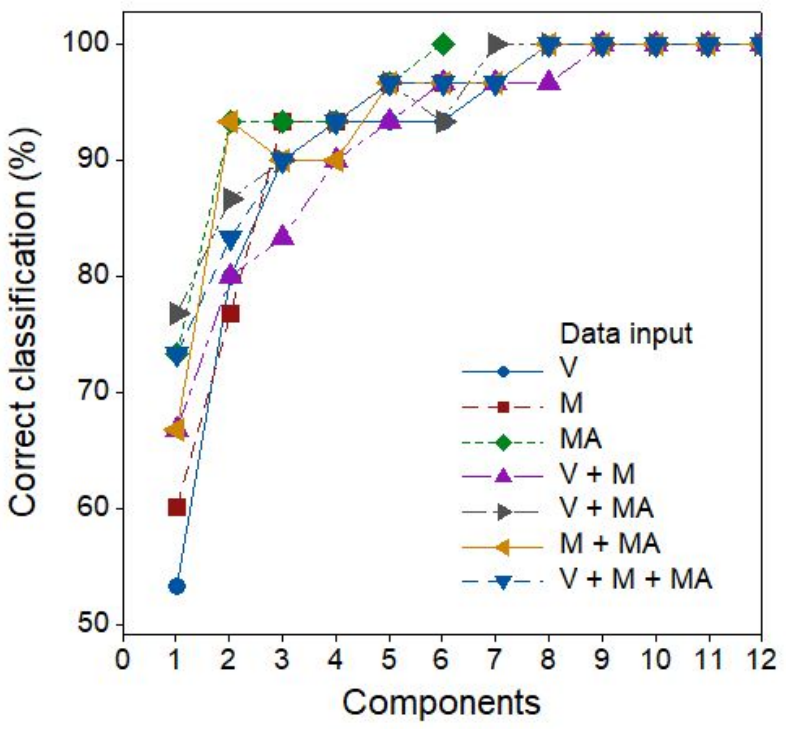

Figure 8: LDA of data inputs. Percentage of correct classification as function of the number of PCs.

from 76.7 - 93.3\% correct (see Figure 8). At 2 PCs, data inputs MA and M + MA show the highest percentage of correct classification. Further increasing the number of PCs used in the LDA results to improvement in classification. Data input MA achieves $100 \%$ correct classification of nonblack fillers with 6 PCs $(100 \%$ of the total variation in the data input). Among the generated data inputs, $\mathrm{V}+\mathrm{MA}$ obtains $100 \%$ correct classification using 7 PCs. For data inputs containing many material properties as predictors, PCA proves to be beneficial in reducing the dimension of the input data, e.g. from 13 material properties to 7 uncorrelated PCs for $\mathrm{V}+\mathrm{MA}$, before usage in LDA.

\section{Conclusion}

Aluminosilicate, bentonite, and silica filler in natural rubber composites can be differentiated using LDA of PCs. Pretreatment of material properties with PCA allows visualization of data patterns that are related to the type of nonblack filler. PCA also removes the correlation among material properties and reduces the number of predictors for LDA. Among the material properties tested as input data, the mechanical properties of the rubber composite after heat aging effectively differentiate and classify the nonblack filler in the samples.

LDA of PCs has already been applied to differentiate and classify important materials. The results of this study demonstrate that the same method can be utilized to identify fillers using the material properties of the rubber composite as input. This multivariate approach has the potential to assist manufacturers in differentiating and selecting other compounding ingredients such as accelerators and process oils in the design of rubber products.

Acknowledgements: The author acknowledges the Office of the Chancellor of the University of the Philippines Diliman, through the Office of the Vice Chancellor for Research and Development, for funding support through the Outright Research Grant. Special thanks are also given to Andreas Eggert of Quarzwerke GmbH - HPF The Mineral Engineers and Eleanor Olegario of Saile Industries Inc. for the kind donation of non-black fillers, and to Ms. Giselle Lou Leuterio for the material testing and data gathering.

\section{References}

[1] Dick, J, Rader, C, Raw Materials Supply Chain for Rubber Products, Carl Hanser Verlag: Munich, 2014.

[2] Mouri, H. In Rubber Technologist's Handbook, White, JR, De, SK, Eds., Rapra Technology Limited: United Kingdom, 2001, p 131.

[3] El-Nashar DE, Ahmed NM, Yehia AA, Mater. Design 2012, 34, 137-142.

[4] Ismail H, Mathialagan M, Polym. Testing 2012, 31, 199-208.

[5] Chakraborty S, Kar S, Dasgupta S, Mukhopadhyay R, Bandyopadhyay S, Joshi M, Ameta SC, Polym. Testing 2010, 29, 679684.

[6] Chakraborty S, Sengupta R, Dasgupta S, Mukhopadhyay R, Bandyopadhyay S, Joshi M, Ameta SC, J. Appl. Polym. Science 2009, 113, 1316-1329.

[7] Chakraborty S, Sengupta R, Dasgupta S, Mukhopadhyay R, Bandyopadhyay S, Joshi M, Ameta SC, Polym. Eng. Science 2009, 49, 1279-1290.

[8] EL-Nashar DE, Gomaa E, Abd-El-Messieh SL, J. Polym. Sci. Part B: Polym. Physics 2009, 47, 1825-1838. 
[9] Sengupta R, Chakraborty S, Bandyopadhyay S, Dasgupta S, Mukhopadhyay R, Auddy K, Deuri AS, Polym. Eng. Science 2007, 47, 1956-1974.

[10] Waddell, WH, Evans, LR. In Rubber Technology Compounding and Testing for Performance, 2nd ed., Dick, JS, Ed., Carl Hanser Verlag: Munich, 2009, p 325.

[11] Waddell WH, Evans LR, Rubber Chem. Technology 1996, 69, 377423.

[12] Dannenberg EM, Rubber Chem. Technology 1982, 55, 860-880.

[13] Zachariah AK, Chandra AK, Mohammed PK, Thomas S, Polym. Testing 2019, 76, 154-165.

[14] Jayaraj S, Egodage SM, Walpalage S, J. Appl. Polym. Science 2018, 135, 46502.

[15] Meera AP, Thomas S, Zachariah AK, Yang W, Polym. Composites 2018, 39, 3110-3118.

[16] Ismail H, Lotfi MNA, Othman N, Mater. Res. Innovations 2018, 1-6.

[17] Muniyadi M, Ismail H, J. Appl. Polym. Science 2013, 130, 44194427.

[18] Albano C, Hernández M, Ichazo MN, González J, DeSousa W, Polym. Bulletin 2011, 67, 653-667.

[19] Pal PK, De SK, Rubber Chem. Technology 1982, 55, 1370-1388.

[20] Domingo C, Arcis RW, Osorio E, Toledano M. Saurina J, Analyst 2000, 125, 2044-2048.

[21] Härdle, W, Simar, L, Applied Multivariate Statistical Analysis, 2nd ed., Springer-Verlag: Berlin, 2007.

[22] Pereira RC, Skrobot VL, Castro EV, Fortes IC, Pasa VM, Energy Fuels 2006, 20, 1097-1102.

[23] Næs T, Mevik BH, J. Chemometrics 2001, 15, 413-426.

[24] Pal, K, Pal, SK, Das, CK, Kim, JK. In Recent Advances in Elastomeric Nanocomposites, Mittal, V, Kim, JK, Pal, K, Eds., Springer-Verlag: Berlin, 2011, p 201.

[25] Bro R, Smilde AK, Anal. Methods 2014, 6, 2812-2831.

[26] Kramer, R, Chemometric Techniques for Quantitative Analysis, Marcel Dekker: New York, 1998.

[27] Vítková G, Prokeš L, Novotný K, Pořízka P, Novotný J, Všianský D, Čelko L, Kaiser J, Spectrochim. Acta, Part B 2014, 101, 191-199.

[28] De Luca M, Terouzi W, Kzaiber F, loele G, Oussama A, Ragno G, Int. J. Food Sci. Technology 2012, 47, 1286-1292.

[29] Rezzi S, Giani I, Héberger K, Axelson DE, Moretti VM, Reniero F, Guillou C, J. Agric. Food. Chemistry 2007, 55, 9963-9968.

[30] Kher A, Mulholland M, Green E, Reedy B, Vib. Spectroscopy 2006, 40, 270-277.

[31] Rezzi S, Axelson DE, Héberger K, Reniero F, Mariani C, Guillou C, Anal. Chim. Acta 2005, 552, 13-24.

[32] Héberger K, Csomós E, Simon-Sarkadi L, J. Agric. Food. Chemistry 2003, 51, 8055-8060.

[33] Dick, JS. In Selecting Methods for a Rubber Test Program, Dick, JS, Ed., ASTM International: Pennsylvania, 2003, p 17.

[34] Wang M, Morris MD, Kutsovsky Y, Kautsch. Gummi Kunststoffe 2008, 61, 107-117.

[35] Yan H, Sun K, Zhang Y, Zhang Y, Fan Y, J. Appl. Polym. Science 2004, 94, 1511-1518. 


\section{A Appendix}

Table 1: Vulcanization characteristics of rubber composites.

\begin{tabular}{|c|c|c|c|c|c|c|c|c|c|}
\hline Sample & Filler & $\begin{array}{c}\text { Proportion } \\
\text { (phr) }\end{array}$ & $\begin{array}{c}\mathrm{ML} \times 10^{2} \\
(\mathrm{Nm})\end{array}$ & $\begin{array}{c}\mathrm{MH} \\
(\mathrm{Nm}) \\
\end{array}$ & $\begin{array}{l}\text { ts1 } \\
\text { (s) }\end{array}$ & $\begin{array}{l}\text { ts2 } \\
(s)\end{array}$ & $\begin{array}{c}\text { tc50 } \\
\text { (s) }\end{array}$ & $\begin{array}{c}\text { tc90 } \\
\text { (s) }\end{array}$ & $\begin{array}{r}\text { CRI } \\
\left(\mathrm{s}^{-1}\right) \\
\end{array}$ \\
\hline 1 & Aluminosilicate & 2.5 & 4.86 & 0.76 & 130 & 154 & 180 & 287 & 0.75 \\
\hline 2 & Aluminosilicate & 5.0 & 6.21 & 0.75 & 140 & 165 & 192 & 313 & 0.68 \\
\hline 3 & Aluminosilicate & 7.5 & 6.10 & 0.73 & 140 & 169 & 193 & 311 & 0.70 \\
\hline 4 & Aluminosilicate & 10.0 & 5.88 & 0.76 & 144 & 169 & 199 & 319 & 0.67 \\
\hline 5 & Aluminosilicate & 12.5 & 6.33 & 0.76 & 148 & 172 & 200 & 322 & 0.67 \\
\hline 6 & Aluminosilicate & 15.0 & 6.21 & 0.82 & 165 & 186 & 214 & 324 & 0.72 \\
\hline 7 & Aluminosilicate & 17.5 & 5.99 & 0.81 & 140 & 165 & 196 & 313 & 0.68 \\
\hline 8 & Aluminosilicate & 20.0 & 6.67 & 0.78 & 133 & 162 & 193 & 324 & 0.62 \\
\hline 9 & Aluminosilicate & 22.5 & 6.55 & 0.82 & 151 & 172 & 202 & 318 & 0.68 \\
\hline 10 & Aluminosilicate & 25.0 & 6.10 & 0.85 & 148 & 169 & 200 & 315 & 0.68 \\
\hline 11 & Bentonite & 2.5 & 4.63 & 0.69 & 158 & 186 & 209 & 327 & 0.71 \\
\hline 12 & Bentonite & 5.0 & 4.07 & 0.62 & 151 & 183 & 200 & 322 & 0.72 \\
\hline 13 & Bentonite & 7.5 & 4.52 & 0.54 & 158 & 200 & 211 & 369 & 0.59 \\
\hline 14 & Bentonite & 10.0 & 3.16 & 0.58 & 137 & 172 & 188 & 353 & 0.55 \\
\hline 15 & Bentonite & 12.5 & 4.07 & 0.45 & 140 & 204 & 188 & 388 & 0.54 \\
\hline 16 & Bentonite & 15.0 & 3.84 & 0.46 & 130 & 197 & 183 & 395 & 0.51 \\
\hline 17 & Bentonite & 17.5 & 4.41 & 0.46 & 137 & 196 & 184 & 384 & 0.53 \\
\hline 18 & Bentonite & 20.0 & 3.62 & 0.48 & 127 & 179 & 175 & 381 & 0.50 \\
\hline 19 & Bentonite & 22.5 & 3.95 & 0.50 & 109 & 158 & 159 & 368 & 0.48 \\
\hline 20 & Bentonite & 25.0 & 7.23 & 0.48 & 130 & 207 & 183 & 430 & 0.45 \\
\hline 21 & Silica & 2.5 & 7.23 & 0.77 & 140 & 172 & 200 & 328 & 0.64 \\
\hline 22 & Silica & 5.0 & 7.23 & 0.75 & 137 & 165 & 193 & 311 & 0.68 \\
\hline 23 & Silica & 7.5 & 7.34 & 0.80 & 172 & 193 & 221 & 330 & 0.73 \\
\hline 24 & Silica & 10.0 & 6.44 & 0.77 & 144 & 172 & 199 & 318 & 0.68 \\
\hline 25 & Silica & 12.5 & 7.23 & 0.77 & 144 & 172 & 200 & 326 & 0.65 \\
\hline 26 & Silica & 15.0 & 7.57 & 0.72 & 211 & 256 & 292 & 444 & 0.53 \\
\hline 27 & Silica & 17.5 & 6.55 & 0.72 & 235 & 274 & 307 & 445 & 0.58 \\
\hline 28 & Silica & 20.0 & 7.01 & 0.81 & 162 & 186 & 218 & 337 & 0.66 \\
\hline 29 & Silica & 22.5 & 8.13 & 0.83 & 162 & 186 & 219 & 340 & 0.65 \\
\hline 30 & Silica & 25.0 & 7.91 & 0.78 & 242 & 281 & 319 & 456 & 0.57 \\
\hline Control & - & - & 6.78 & 0.70 & 140 & 169 & 190 & 301 & 0.76 \\
\hline
\end{tabular}


Table 2: Mechanical properties of rubber composites before heat aging.

\begin{tabular}{|c|c|c|c|c|c|c|c|c|}
\hline Sample & Filler & $\begin{array}{c}\text { Proportion } \\
\text { (phr) }\end{array}$ & $\begin{array}{c}100 \% \text { Mod } \\
(\mathrm{MPa})\end{array}$ & $\begin{array}{c}200 \% \mathrm{Mod} \\
(\mathrm{MPa})\end{array}$ & $\begin{array}{c}300 \% \text { Mod } \\
(\mathrm{MPa})\end{array}$ & $\begin{array}{c}\text { TS } \\
(\mathrm{MPa})\end{array}$ & $\begin{array}{l}\text { SB } \\
(\%)\end{array}$ & Hardness \\
\hline 1 & Aluminosilicate & 2.5 & 0.7 & 1.2 & 1.8 & 18.9 & 1076.5 & 40.4 \\
\hline 2 & Aluminosilicate & 5.0 & 0.7 & 1.2 & 1.8 & 18.4 & 1150.0 & 36.6 \\
\hline 3 & Aluminosilicate & 7.5 & 0.7 & 1.2 & 1.9 & 21.1 & 1096.8 & 37.3 \\
\hline 4 & Aluminosilicate & 10.0 & 0.7 & 1.2 & 1.9 & 19.0 & 1061.9 & 38.4 \\
\hline 5 & Aluminosilicate & 12.5 & 0.8 & 1.3 & 2.0 & 17.8 & 911.9 & 39.6 \\
\hline 6 & Aluminosilicate & 15.0 & 0.8 & 1.5 & 2.3 & 19.6 & 885.8 & 40.5 \\
\hline 7 & Aluminosilicate & 17.5 & 0.8 & 1.4 & 2.1 & 18.8 & 957.2 & 39.2 \\
\hline 8 & Aluminosilicate & 20.0 & 0.7 & 1.4 & 2.1 & 19.1 & 963.0 & 40.7 \\
\hline 9 & Aluminosilicate & 22.5 & 0.8 & 1.5 & 2.2 & 18.6 & 957.3 & 39.5 \\
\hline 10 & Aluminosilicate & 25.0 & 0.8 & 1.5 & 2.2 & 18.0 & 975.5 & 41.0 \\
\hline 11 & Bentonite & 2.5 & 0.7 & 1.1 & 1.7 & 19.0 & 1047.5 & 36.0 \\
\hline 12 & Bentonite & 5.0 & 0.6 & 1.0 & 1.4 & 18.3 & 1255.0 & 34.2 \\
\hline 13 & Bentonite & 7.5 & 0.5 & 0.9 & 1.2 & 15.0 & 1200.3 & 30.7 \\
\hline 14 & Bentonite & 10.0 & 0.6 & 1.0 & 1.4 & 16.8 & 1217.6 & 33.6 \\
\hline 15 & Bentonite & 12.5 & 0.5 & 0.8 & 1.1 & 12.6 & 1180.4 & 29.9 \\
\hline 16 & Bentonite & 15.0 & 0.5 & 0.8 & 1.2 & 11.8 & 1119.1 & 30.6 \\
\hline 17 & Bentonite & 17.5 & 0.5 & 0.8 & 1.2 & 11.8 & 1106.4 & 31.0 \\
\hline 18 & Bentonite & 20.0 & 0.5 & 0.9 & 1.2 & 11.0 & 1063.1 & 31.6 \\
\hline 19 & Bentonite & 22.5 & 0.5 & 0.9 & 1.2 & 10.0 & 1069.8 & 30.8 \\
\hline 20 & Bentonite & 25.0 & 0.6 & 1.0 & 1.4 & 13.6 & 1045.9 & 34.1 \\
\hline 21 & Silica & 2.5 & 0.8 & 1.4 & 2.1 & 23.6 & 1133.4 & 39.4 \\
\hline 22 & Silica & 5.0 & 0.7 & 1.3 & 1.9 & 21.8 & 1099.2 & 37.8 \\
\hline 23 & Silica & 7.5 & 0.7 & 1.3 & 2.0 & 20.5 & 991.4 & 38.3 \\
\hline 24 & Silica & 10.0 & 0.8 & 1.4 & 2.1 & 20.7 & 956.1 & 38.3 \\
\hline 25 & Silica & 12.5 & 0.7 & 1.3 & 2.0 & 20.3 & 984.2 & 38.5 \\
\hline 26 & Silica & 15.0 & 0.7 & 1.2 & 1.8 & 20.7 & 1091.1 & 38.4 \\
\hline 27 & Silica & 17.5 & 0.7 & 1.2 & 1.8 & 20.3 & 1136.8 & 37.0 \\
\hline 28 & Silica & 20.0 & 0.8 & 1.5 & 2.3 & 21.5 & 940.7 & 40.1 \\
\hline 29 & Silica & 22.5 & 0.9 & 1.6 & 2.5 & 23.1 & 930.4 & 41.3 \\
\hline 30 & Silica & 25.0 & 0.8 & 1.5 & 2.3 & 22.5 & 951.1 & 41.1 \\
\hline Control & - & - & 0.7 & 1.2 & 1.8 & 22.0 & 1020.1 & 38.2 \\
\hline
\end{tabular}


Table 3: Mechanical properties of rubber composites after heat aging.

\begin{tabular}{|c|c|c|c|c|c|c|c|c|}
\hline Sample & Filler & $\begin{array}{c}\text { Proportion } \\
\text { (phr) }\end{array}$ & $\begin{array}{c}100 \% \mathrm{Mod} \\
(\mathrm{MPa})\end{array}$ & $\begin{array}{c}200 \% \mathrm{Mod} \\
(\mathrm{MPa})\end{array}$ & $\begin{array}{c}300 \% \mathrm{Mod} \\
(\mathrm{MPa})\end{array}$ & $\begin{array}{c}\text { TS } \\
\text { (MPa) }\end{array}$ & $\begin{array}{l}\text { SB } \\
\text { (\%) }\end{array}$ & Hardness \\
\hline 1 & Aluminosilicate & 2.5 & 0.8 & 1.4 & 2.2 & 14.0 & 823.7 & 40.6 \\
\hline 2 & Aluminosilicate & 5.0 & 0.8 & 1.4 & 2.2 & 17.7 & 959.9 & 39.7 \\
\hline 3 & Aluminosilicate & 7.5 & 0.7 & 1.3 & 2.0 & 12.4 & 869.9 & 36.6 \\
\hline 4 & Aluminosilicate & 10.0 & 0.8 & 1.4 & 2.1 & 11.8 & 846.1 & 38.7 \\
\hline 5 & Aluminosilicate & 12.5 & 0.8 & 1.4 & 2.1 & 12.0 & 789.4 & 40.9 \\
\hline 6 & Aluminosilicate & 15.0 & 0.8 & 1.6 & 2.3 & 11.6 & 776.4 & 39.9 \\
\hline 7 & Aluminosilicate & 17.5 & 0.8 & 1.5 & 2.3 & 11.1 & 786.3 & 39.3 \\
\hline 8 & Aluminosilicate & 20.0 & 0.8 & 1.6 & 2.3 & 12.8 & 800.2 & 40.8 \\
\hline 9 & Aluminosilicate & 22.5 & 0.9 & 1.6 & 2.4 & 11.4 & 752.1 & 40.9 \\
\hline 10 & Aluminosilicate & 25.0 & 0.8 & 1.5 & 2.2 & 8.0 & 678.3 & 38.4 \\
\hline 11 & Bentonite & 2.5 & 0.7 & 1.2 & 1.8 & 9.6 & 775.3 & 35.1 \\
\hline 12 & Bentonite & 5.0 & 0.6 & 1.0 & 1.4 & 10.9 & 961.3 & 31.7 \\
\hline 13 & Bentonite & 7.5 & 0.5 & 0.9 & 1.4 & 11.1 & 1021.2 & 31.0 \\
\hline 14 & Bentonite & 10.0 & 0.6 & 1.0 & 1.4 & 7.7 & 839.1 & 32.0 \\
\hline 15 & Bentonite & 12.5 & 0.5 & 0.8 & 1.2 & 6.3 & 854.0 & 29.0 \\
\hline 16 & Bentonite & 15.0 & 0.4 & 0.8 & 1.1 & 6.4 & 870.6 & 27.7 \\
\hline 17 & Bentonite & 17.5 & 0.5 & 0.8 & 1.1 & 7.3 & 904.1 & 28.1 \\
\hline 18 & Bentonite & 20.0 & 0.5 & 0.8 & 1.2 & 6.4 & 851.3 & 28.7 \\
\hline 19 & Bentonite & 22.5 & 0.4 & 0.8 & 1.1 & 3.2 & 648.1 & 26.0 \\
\hline 20 & Bentonite & 25.0 & 0.4 & 0.7 & 1.0 & 5.7 & 896.6 & 26.6 \\
\hline 21 & Silica & 2.5 & 0.8 & 1.4 & 2.0 & 16.1 & 1001.0 & 36.8 \\
\hline 22 & Silica & 5.0 & 0.8 & 1.5 & 2.3 & 17.1 & 923.2 & 37.3 \\
\hline 23 & Silica & 7.5 & 0.8 & 1.5 & 2.3 & 17.0 & 899.8 & 38.1 \\
\hline 24 & Silica & 10.0 & 0.8 & 1.5 & 2.4 & 17.1 & 845.7 & 39.4 \\
\hline 25 & Silica & 12.5 & 0.9 & 1.5 & 2.4 & 19.5 & 948.2 & 39.5 \\
\hline 26 & Silica & 15.0 & 0.8 & 1.4 & 2.1 & 15.7 & 902.8 & 37.9 \\
\hline 27 & Silica & 17.5 & 0.8 & 1.4 & 2.1 & 16.8 & 999.2 & 36.8 \\
\hline 28 & Silica & 20.0 & 0.9 & 1.7 & 2.6 & 18.6 & 895.4 & 41.0 \\
\hline 29 & Silica & 22.5 & 1.0 & 1.8 & 2.9 & 17.5 & 811.0 & 42.4 \\
\hline 30 & Silica & 25.0 & 0.9 & 1.6 & 2.5 & 17.0 & 865.2 & 40.8 \\
\hline Control & - & - & 0.7 & 1.2 & 1.9 & 16.5 & 902.6 & 38.1 \\
\hline
\end{tabular}

